\title{
The development of a free operant light-dark discrimination using intracranial reinforcement
}

\author{
THOMAS E. SAWICKY and CHARLES J. MELISKA \\ Monmouth College, Monmouth, Ilinois 61462
}

\begin{abstract}
Four experimentally naive rats, chronically implanted for self-stimulation, were tested for their ability to acquire a visual discrimination in a free operant situation. Single reinforcing brain shocks were available on a VR $40 \%$ schedule during 2 -min $S^{D}$ periods, which were alternated randomly with $2-\min \mathrm{S}^{\Delta}$ periods. Acquisition and extinction measures indicated that stimulus control was rapidly established under these circumstances.
\end{abstract}

Since Olds and Milner (1954) first demonstrated that intracranial electrical stimulation (ICS) could serve as a powerful reinforcer for instrumental responding, many studies have dealt with comparisons of the behavioral effects of ICS and conventional rewards such as food and water (Olds, 1956; Brady \& Conrad, 1960; see Gallistel, 1964, for a review of studies). While ICS appears to be unsurpassed for maintaining responding on continuous reinforcement (CRF) schedules, it has been frequently observed that, paradoxically, performance becomes unstable whenever ICS is available only intermittently. For example, Gallistel (1964) cites evidence that it is difficult to maintain responding for ICS with FR schedules of higher than 10:1 or with VI schedules with a mean greater than $16-30 \mathrm{sec}$. Evidently, in contrast to conventional rewards, extinction of responding typically occurs quite rapidly when ICS is withheld (Seward, Uyeda, \& Olds, 1960; Brodie, Moreno, Malis, \& Boren, 1960). Deutsch (1960) has attributed this feature to a rapidly decaying ICS-induced drive state which diminishes quickly when ICS is discontinued.

More recently, however, Pliskoff, Wright, and Hawkins (1965) reported that they were able to establish responding on multiple schedules having relatively "lean" FI, FR, or DRL components" (e.g., FI $10 \mathrm{~min}$ ) by allowing Ss to receive $20-100$ continuous reinforcements at the termination of the intermittent component. Similarly, Brown and Trowill (1970) maintained responding on VI 60-sec and FI 60-sec schedules by allowing five sequential CRF responses (each providing $0.75 \mathrm{sec}$ of ICS) at the end of the interval. Thus, the results of Pliskoff et al (1965) and of Brown and Trowill (1970) suggest that stable responding can be maintained, even with long intervals between reinforcements, but only when the reinforcer consists of a series of brain shocks lasting a matter of seconds.

The relative instability of responding under partial reinforcement with ICS raises the question of whether animals can learn a standard discrimination, using single rather than multiple brain shocks, in a situation where SD periods are alternated with long nonreinforcement
$\left(\mathrm{S}^{\Delta}\right)$ periods. The present study was undertaken to determine whether rats could learn a visual discrimination using brief $(0.20 \mathrm{sec})$ ICS reinforcements, available on a short VR schedule, during widely spaced SD periods. A modification of the Smith and Hoy (1954) procedure was used. This method allows the $S$ to receive reinforcement on a partial reinforcement schedule during some 2-min intervals, in the presence of one stimulus $\left(\mathrm{S}^{\mathrm{D}}\right)$, and no reinforcement during other 2-min intervals, in the presence of another stimulus $\left(\mathrm{S}^{\Delta}\right)$. Using food reward, Smith and Hoy (1954) found that discriminative responding developed gradually, with the total number of responses emitted (i.e., during SD and $S^{\Delta}$ combined) remaining relatively constant throughout training.

\section{METHOD}

\section{Subjects}

The Ss were four naive albino rats of the Harlan/Wistar strain, approximately 120 days old at the time of surgery. Food and water were available ad lib until the time of surgery, after which Ss were fed a quantity of food sufficient to maintain them at their presurgical weights.

\section{Surgery}

The Ss were chronically implanted under Nembutal anesthesia with double coil wire electrodes (Plastic Products, Roanoke, Va.). Electrodes were insulated except at the tip and were aimed at the medial forebrain bundle of the lateral hypothalamus (1.9 $\mathrm{mm}$ lateral to the midline, $5.0 \mathrm{~mm}$ anterior, and inserted to a depth of $8.9 \mathrm{~mm}$; DrGroot, 1959).

\section{Apparatus}

Testing took place in a single-lever Skinner box modified to accommodate self-stimulation studies. The discriminative stimulus was delivered via a $6-\mathrm{W}$ bulb (G.E. $24 \mathrm{~V}$ ) mounted within the wall of the box about 4 in. above the bar. Ambient illumination during testing was less than $1.0 \mathrm{fc}$.

Electrical stimulation was delivered from a Grass stimulator (Model S4K) by means of a cable swivel that allowed the rat to move freely within the box. The stimulation provided biphasic square-wave stimulation of $100 \mathrm{~Hz}$; each pulse train was $200 \mathrm{msec}$ in duration. Stimulation currents (from 75 to 


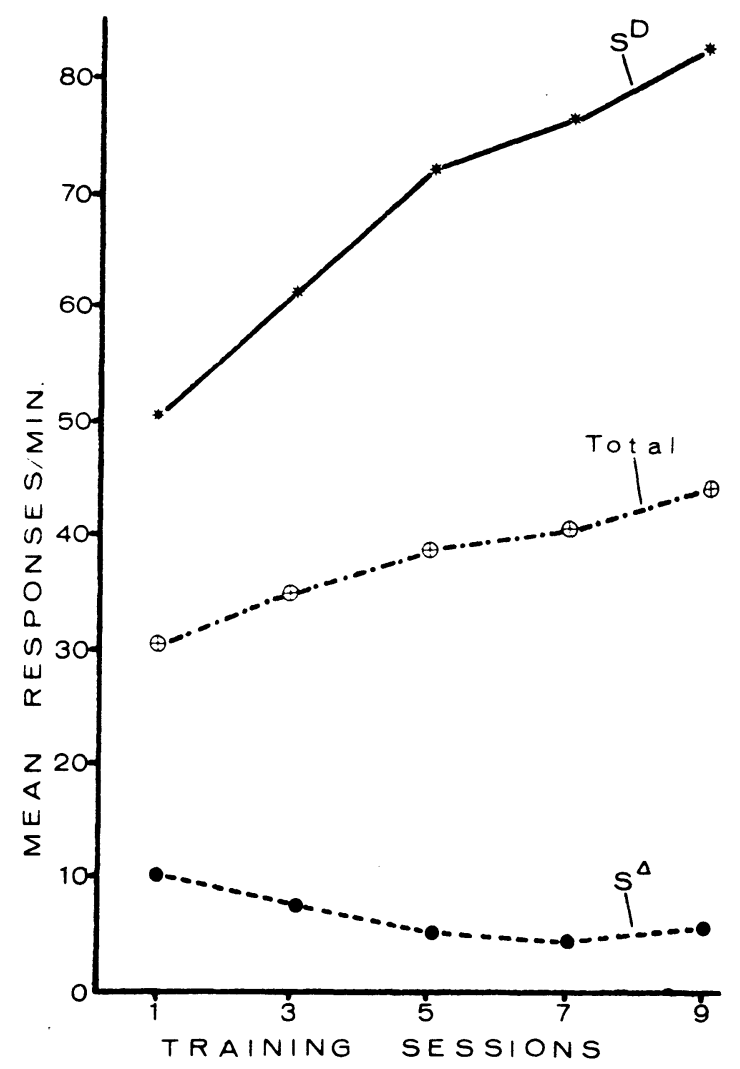

Fig. 1. Mean response rates for $S^{D}, S^{\Delta}$, and $S^{D}+S^{\Delta}$ combined (total) across training sessions.

130 microA) were set independently for each $S$ at a value which produced sustained performance and were maintained at that level throughout the experiment.

\section{Procedure}

About 1 week after surgery, each $S$ was screened for self-stimulation. The first four Ss which could be shaped to barpress were then given $20 \mathrm{~min}$ of training under CRF with the discriminative stimulus $\left(\mathrm{SD}^{D}\right)$ present. During the next 2 days, Ss were shaped to respond on a VR schedule.

Discrimination training was begun on the fourth day. Each session consisted of a series of 202 -min trials. Either $\mathrm{S}^{\mathbf{D}}$ or $\mathrm{S}^{\Delta}$ was present continuously throughout each trial. For half the Ss, the light-on was $S^{D}$; for the other half, light-off was $S^{D}$. In order to prevent the occurrence of temporal discrimination, the sequence of $S^{D}$ and $S^{\Delta}$ periods was randomized with the constraints that each appear 10 times in a session and that neither appear more than three times in a row. Each $\mathrm{S}$ received nine consecutive 40-min daily training sessions followed by one extinction session on Day 10, during which all reinforcement was withheld during testing.

\section{RESULTS}

Pilot runs indicated that VR schedules with fewer than $40 \%$ reinforced responses (e.g., VR 30\%) would support barpressing for ICS but would not sustain performance during discrimination training in some animals. Therefore, all Ss were trained with the VR $40 \%$ schedule in effect during $S^{D}$ periods.
Since the data from all four Ss was substantially the same, their scores were combined for statistical analyses. Three separate two-factor ANOVAs and appropriate Duncan's multiple range tests were performed on the number of responses/minute made during $\mathrm{SD}^{\mathrm{D}}, \mathrm{S}^{\Delta}$, and total $\left(\mathrm{S}^{\mathrm{D}}+\mathrm{S}^{\Delta}\right.$ combined). The factors tested were the nature of the positive stimulus (light-positive vs dark-positive) and training sessions. Figure 1 illustrates that as training progressed, response rate during $S^{\Delta}$ progressively declined, while response rate during $\mathrm{SD}$ progressively increased. The decline in responding during $\mathrm{S}^{\Delta}$ was significant between Sessions 1 and $3(\mathrm{p}<.05)$ and between Sessions 3 and $5(\mathrm{p}<.05)$, but Sessions 5 , 7 , and 9 did not differ significantly from each other; hence, the rate of responding during $S^{\Delta}$ had reached a minimum by the end of the fifth day (i.e., after 200 min) of training.

Responding to the presence of SD continued to rise steadily across all nine sessions, as Fig. 1 indicates. Significant increases occurred between Sessions 1 and 3 $(\mathrm{p}<.05), 3$ and $5(\mathrm{p}<.05)$, and 5 and $9(\mathrm{p}<.05)$; Sessions 5 and 7 and Sessions 7 and 9 were not significantly different.

Since the increase in response rate during $S^{D}$ was substantially greater than the decrease in $S^{\Delta}$ responses, especially between Sessions 5 and 9, the total number of responses did not remain constant across sessions. Figure 1 shows the progressive increase in mean total number of responses which occurred with training. The increase between Sessions 1 and 5 was significant $(p<.05)$, as was the increase between Sessions 5 and 9 $(\mathrm{p}<.05)$.

Figure 2 provides another measure of the improvement in discrimination performance across sessions. The discrimination index $\left(D I=S^{D} / S^{D}+S^{\Delta}\right)$ provides a measure of the proportion of the total number of responses that occurred during $\mathrm{S}^{\mathrm{D}}$. The figure illustrates that the DI exceeded .80 even for the first training session and increased progressively to a maximum of .937 by the seventh session. Differences



Fig. 2. Mean discrimination index (DI $\left.=S^{D} / S^{D}+S^{\Delta}\right)$ across training sessions. 
between sessions were subjected to ANOVA (with arcsine transformation) and Duncan's multiple range tests, which revealed a significant improvement between Sessions 1 and $3(\mathrm{p}<.01)$ and 3 and $5(\mathrm{p}<.01)$, but not thereafter. In short, the DI indicates that discriminative performance had become virtually asymptotic by the end of the fifth day of training.

In order to verify the fact that the Ss were actually responding to the discriminative stimuli and not to the presence of the reinforcer itself, an extinction session was run immediately after the ninth training session. Figure 3 shows individual cumulative response curves during $S^{D}$ and $S^{\Delta}$ within this session. In each case, the wide divergence of the two curves clearly illustrates that Ss responded at a much higher rate in the presence of $\mathrm{SD}^{\mathrm{D}}$ than during $S^{\Delta}(\bar{X}=77.25$ vs 13.50 responses/session, respectively). ANOVA indicated that this difference was significant $(F=51.64, p<.01)$, verifying the fact that Ss responded more often in the presence of $S^{D}$ than in the presence of $S^{\Delta}$, even in the absence of the reinforcer.

(In all analyses, differences between light-positive and dark-positive conditions were small and statistically nonsignificant, as were all interactions.)

\section{DISCUSSION}

The acquisition and extinction data clearly indicate that maximum differential responding to $\mathrm{S}^{\mathrm{D}}$ and $\mathrm{S}^{\Delta}$ was achieved within about $3 \mathrm{~h}$ of training, using single ICS reinforcements on a partial reinforcement schedule. This rapid acquisition contrasts with earlier studies using conventional rewards (Smith \& Hoy, 1954; Pierrel, Sherman, Blue, \& Hegge, 1970), which report high discrimination accuracy only after several hours of training. However, this discrepancy is probably attributable to at least three important performance-related factors. First, as Blough (1966) has observed, whenever the reinforcer is available on a short variable ratio, the occurrence of one reinforcement provides the $\mathrm{S}$ with a cue that more reinforcements are available. Hence, Ss may increase responding very rapidly during $\mathrm{S}^{\mathrm{D}}$ periods without actually learning the discrimination the $\mathrm{E}$ intended. Perhaps the rapid differentiation of responding observed in the present study is largely attributable to this reinforcement-signaling property of the short VR schedule that was used. This would account for the very high accuracy of performance observed even on the first day of discrimination training. However, even granting the likelihood of this reinforcement-signaling phenomenon, the extinction data clearly shows that the Ss continued to respond differentially to $\mathrm{SD}^{\mathrm{D}}$ and $\mathrm{S}^{\Delta}$, even in the absence of reinforcement, by the end of the ninth training session.

The other two factors which probably contributed to the rapid improvement in discrimination performance relate to the special characteristics of ICS-rewarded
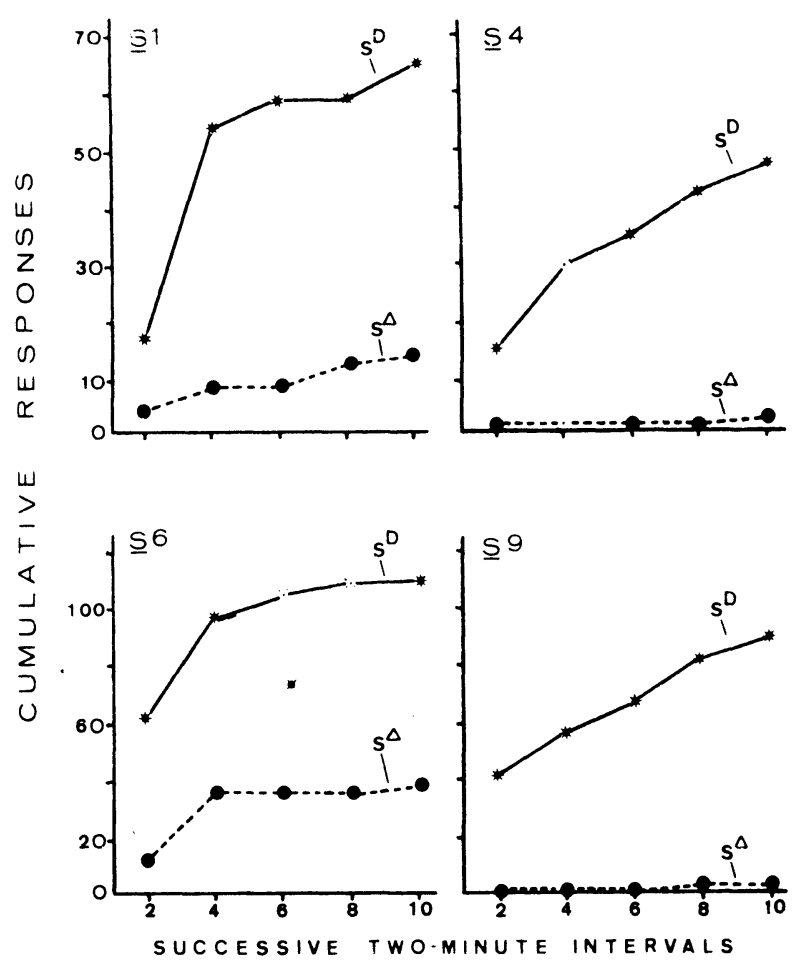

Fig. 3. Extinction session (Day 10): Individual cumulative response curves during $S^{D}$ and $S^{\Delta}$ across successive 2-min intervals.

responding: i.e., rapid extinction when reinforcement is withheld and rapid reacquisition when reinforcement is available again. These two factors would explain the rapid decline in responding during the $S^{\Delta}$ periods and the rapid resumption of high rates of responding during the SD periods, which were surprisingly evident even on the first day of discrimination training. Furthermore, the progressive increases in $\mathrm{SD}^{\mathrm{D}}$ responses were apparently due to the fact that as stimulus control developed, responding was resumed more and more quickly at the onset of $\mathrm{SD}$, resulting in an increasing number of responses during the $\mathrm{SD}$ intervals as training progressed.

In conclusion, the results of the present study indicate that rats can readily learn a visual discrimination in a free operant situation involving long $S^{\Delta}$ intervals (up to $4 \mathrm{~min}$ ), using only single brain shocks delivered on a partial reinforcement schedule. This outcome was not entirely anticipated in view of the reports of Pliskoff et al (1965) and of Brown and Trowill (1970), which indicated that responding cannot be sustained with long delays between ICS reinforcements unless multiple brain shocks are given. Future investigations would do well to explore the possibility that because of its special properties, ICS may produce faster acquisition of stimulus control than conventional reinforcers.

\section{REFERENCES}

Blough, D. S. The study of animal sensory processes by operant methods. In W. K. Honig (Ed.), Operant behavior: Areas of research and application. New York: 
Appleton-Century-Crofts, 1966.

Brady, J. V., \& Conrad, D. G. Some effects of limbic system self-stimulation upon conditioned emotional behavior. Journal of Comparative \& Physiological Psychology, 1960, 53, 128-137.

Brodie, D., Moreno, O. M., Malis, J. L., \& Boren, J. J. Nonreversibility of the appetitive characteristics of intracranial stimulation. American Journal of Physiology, 1960, 199, 707-709.

Brown, S., \& Trowill, J. A. Lever-pressing performance for brain stimulation on FI and VI schedules in a single-lever situation. Psychological Reports, 1970, 26, 699-706.

DeGroot, J. The rat forebrain in stereotaxic coordinates. Amsterdam: N.V. Noord-Hollandsche Uitgevers Maatschappij, 1963.

Deutsch, J. A. The structural basis of behavior. Chicago: University of Chicago Press, 1960.

Gallistel, C. R. Electrical self-stimulation and its theoretical implications. Psychological Bulletin, 1964, 61, 23-34.

Olds, J. Runway and maze behavior controlled by basomedial forebrain stimulation in the rat. Journal of Comparative \&
Physiological Psychology, 1956, 49, 507-512.

Olds, J., \& Milner, P. Positive reinforcement produced by electrical stimulation of septal area and other regions of the rat brain. Journal of Comparative \& Physiological Psychology, 1954, 47, 419-427.

Pierrel, R., Sherman, J. G., Blue, S., \& Hegge, F. W. Auditory discrimination: A three-variable analysis of intensity effects. Journal of the Experimental Analysis of Behavior, 1970, 13, 17-35.

Pliskoff, S. S., Wright, J. E., \& Hawkins, T. D. Brain stimulation as a reinforcer: Intermittent schedules. Journal of the Experimental Analysis of Behavior, 1965, 8, 75-88.

Seward, J. P., Uyeda, A. A., \& Olds, J. Resistance to extinction following cranial self-stimulation. Journal of Comparative \& Physiological Psychology, 1960, 53, 224-227.

Smith, M. H., \& Hoy, W. J. Rate of response during operant discrimination. Journal of Experimental Psychology, 1954, $48,259-266$.

(Received for publication September 20, 1972; accepted October 31, 1972.) 